\title{
Experimental and numerical analysis of aramid fiber laminates with DCPD resin matrix subjected to impact tests
}

\author{
Miroslaw Bocian 1,*, Joanna Pach $^{2}$, Krzysztof Jamroziak ${ }^{1}$, Mariusz Kosobudzki ${ }^{3}$, \\ Slawomir Polak ${ }^{4}$, Dariusz $\mathrm{Pyka}^{4}$, Adam Kurzawa ${ }^{2}$, and Janusz Kurowski ${ }^{5}$ \\ ${ }^{1}$ Wroclaw University of Science and Technology, Department of Mechanics, Materials Science and \\ Engineering, Smoluchowskiego 25, Wroclaw 50-370, Poland \\ ${ }^{2}$ Wroclaw University of Science and Technology, Chair of Foundry, Polymers and Automation, \\ Laboratory of Plastics, Lukasiewicza 5, Wroclaw 50-371, Poland \\ ${ }^{3}$ General Tadeusz Kosciuszko Military Academy of Land Forces, Czajkowskiego 109, Wroclaw \\ 51-150, Poland \\ ${ }^{4}$ Wroclaw University of Science and Technology, Department of Metal Forming and Metrology, \\ Lukasiewicza 5, Wroclaw 50-371, Poland \\ ${ }^{5}$ The company IM/kompozyty, Topolowa 5, Stanowice 55-200, Poland
}

\begin{abstract}
Research for innovative composite material solutions for impact absorbers is focused on the analysis of their ability to absorb impact energy. For this purpose, aramid fiber laminate with DCPD resin matrix was prepared. Laminate samples were tested on the drop test and were subjected to ballistic loads. The laminate structure was modeled with ABAQUS software with the objective to optimize and estimate the ability to absorb impact energy in the range of high speeds $(350 \mathrm{~m} / \mathrm{s})$.
\end{abstract}

\section{Introduction}

Composite parameters depend on the properties of the constituent phases, their number, and volume of the composite, the orientation of the reinforcement in the matrix and the geometrical characteristics of these phases. For this reason, it is important to pay attention to the strength characteristics of the dispersed phase and the continuous phase (matrix). This refers to identifying various properties, such as mechanical, technological, physical and chemical [1-3].

Optimization in the laminate production, particularly ballistic laminates, is focused on the use of thermoplastic polymers [4,5] and elastomers [6] for matrixes. The common use of these type of matrixes applies to reinforcements based primarily on aramid and polyethylene fibers, where the process of absorbing the energy of the impact loads (ballistic) is oriented mainly on the delamination of the matrix until it fractures. According to some studies $[7,8]$, the matrix is capable of dispersing up to $35 \%$ of the impact energy as a consequence of breaking. The mechanism of ballistic impact energy dissipation in case of a single layer will exceed the strength of the matrix in case of shearing and bending, and at

${ }^{*}$ Corresponding author: miroslaw.bocian@pwr.edu.pl 
the layers edge of the laminate delamination is initiated, this process can occur with a specific progress of fractures [9]. The amount of energy causing delamination of the matrix is much lower than the critical amount of energy causing the destruction of the fiber [10]. This process is divided into two stages [11]. In the first stage, a high energy and velocity projectile on impact causes fiber shearing and matrix exfoliation in the composite. In the second stage, as the projectile decelerates, the remaining impact energy is involved in the process of delamination of the matrix. Composite fibers located underneath the concentration of the impact energy in the deeper layers are subject to stretching.

Authors have observed that, by replacing recently used and described in several papers hardened matrixes with a thermoplastic or an elastomer matrix, it is possible to perform optimization of the ballistic laminate in terms of both the volume efficiency, by the reduction of the reinforcement layers, and a local dissipation of impact energy. As an example, referred work [12] is focused on the analysis of using a styrene-butadiene-styrene (SBS) copolymer based matrix.

In this paper, the main focus is on the tests of dicyclopentadiene (DPCD) type of laminate matrix. Reinforcement of the laminate samples were prepared from aramid fibers. The laminates were subjected to tests for the impact energy dissipation in both ballistic tests and numerical analyzes.

\section{Experiments}

\subsection{Materials}

To prepare a DCPD matrix laminate sample, Twaron ${ }^{\circledR}$ aramid fabric of $280 \mathrm{~g} / \mathrm{m}^{2}$ basic weight and plain weave structure was used as reinforcement. The fabric thickness of 0.4 $\mathrm{mm}$ has a fiber density of approx. $1.45 \mathrm{~g} / \mathrm{cm}^{3}$, and a fiber diameter of $12 \mu \mathrm{m}$. For laminate production 12 layers of fabric were used, where the sample had a thickness of $4.4 \mathrm{~mm}$ and a weight of $224 \mathrm{~g}$. Modified dicyclopentadiene (DCPD) was used as the matrix resin, which is a by-product secreted from processing crude oil. The polymerization process was carried out in the presence of a second generation Grubbs catalyst [13].

Applied in this paper matrix is characterized by improved parameters of static tensile and bending strength, high relative elongation at rupture and high compressive strength in comparison to other types of resins. Material after super saturation with the DCPD was subjected to pressure at room temperature $\left(21^{\circ} \mathrm{C}\right)$ at a pressure of approx. $1.5 \mathrm{MPa}$ and was left for 12 hours. Resultant laminate was cut into 100x100 mm pieces (used size was dependent on the coupling at the test stand) in order to perform energy-intensive testing on a drop tower and on a ballistic track.

\subsection{Impact test}

Perforation of used samples in the resilience test was performed using a Dynatup Instron 9250 drop tower equipped with a HV Instron Dynatup 1-800-I-U-SERVE impactor. The impact test stand is shown in Figure 1.

The geometry of the impactor, which allows executing concentrated loads, is similar to the geometry of the Parabellum $9 \times 19 \mathrm{~mm}$ pistol bullet. The accessories used at the test stand allow registration of parameters such as the impact force, maximum deflection and impact velocity. The value of the energy absorbed by the laminate is determined, based on the force curve as a function of time. The value of kinetic energy of the impactor was determined experimentally and adjusted to $150 \mathrm{~J}$. The impact tests were performed at $21^{\circ} \mathrm{C}$ for 6 samples. 


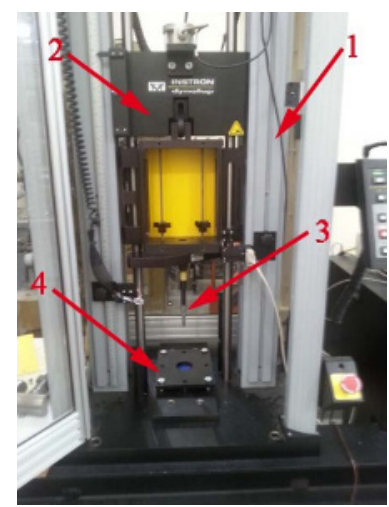

Fig. 1. The impact testing stand: 1 - the impact machine, 2 - the striking head, 3 - the impactor, 4 - catch for mounting samples.

\subsection{Ballistic test}

Ballistic tests consisted of shootings Parabellum 9x19 mm ammunition into laminate samples using a Polish production pm-84P Glauberyt type machine gun. Tests were carried out according to the specifications of the European norm CEN EN 1522. Six shooting tests were conducted, for which the average muzzle velocity of the projectile was $v_{0}=349.6 \mathrm{~m} / \mathrm{s}$. The speed of the projectiles was measured with a Doppler Weibel SL-525E radar and was mirrored by a Chronograph CED Millennium measurement gate.

Samples were mounted in a special holder, supported on the base with a ballistic plasticine. The plasticity of the base was verified by dropping three times a steel weight (cylinder with a diameter of $\varnothing 44 \mathrm{~mm}$ with a spherical end) of $1 \mathrm{~kg}$ from a height of $2 \mathrm{~m}$, where a cavity of $25 \pm 3 \mathrm{~mm}$ should be the result.

\subsection{Numerical analysis}

Ballistic simulations performed in ABAQUS program were narrowed in order to simplify the numerical model of the projectile, namely, including in the analysis only the core of the projectile and the translation speed, that is, omission of the projectile rotation [14]. Kinetic energy of the projectile was realized by considering the initial speed $v_{0}=349.6 \mathrm{~m} / \mathrm{s}$ and the mass of the projectile as $8 \mathrm{~g}$, thus the initial kinetic energy is as $488.9 \mathrm{~J}$.

Homogenization of modeled object was made in order to determine the mechanical properties of the laminate. Material data used for the simulation are summarized in Table 1.

Table 1. Characteristics of the projectile material properties, aramid material and DCPD.

\begin{tabular}{|c|c|c|c|c|c|c|c|c|}
\hline \multirow{2}{*}{ Specification } & $E$ & $v$ & $\rho$ & $A$ & $B$ & $n$ & $S I G Y$ & $F S$ \\
\cline { 2 - 9 } & {$[\mathrm{GPa}]$} & {$[-]$} & {$\left[\mathrm{kg} / \mathrm{m}^{3}\right]$} & {$[\mathrm{MPa}]$} & {$[\mathrm{MPa}]$} & {$[-]$} & {$\left[\mathrm{N} / \mathrm{m}^{2}\right]$} & {$[-]$} \\
\hline $\begin{array}{c}\text { Core lead } \\
\text { (alloy of Pb1 and } \\
\text { antimony) }\end{array}$ & 16 & 0.42 & 11300 & 24 & 300 & 1 & - & - \\
\hline Jacket (brass M90) & 115 & 0.31 & 8940.9 & 206 & 505 & 0.42 & - & - \\
\hline Twaron & 115 & 0.3 & 1450 & - & - & - & $3.6 \mathrm{E}+9$ & 0.04 \\
\hline DCPD & 3.1 & - & 980 & - & - & - & - & - \\
\hline
\end{tabular}

Where: $E$ - Young's modulus, $v$ - Poisson's ratio, $A$ - yield at zero plastic strain, $B$ - hardening constant, $n$ - hardening exponent, $S I G Y$ - Yield strength, $F S$ - Effective plastic strain, failure criterion. 


\section{Results and discussion}

\subsection{Responses under impact loading and ballistic}

Based on carried out piercing drop tests of the laminate samples and firing on the shooting range (Figure 2) samples were subjected to a thorough analysis in terms of absorbed impact energy.

a)
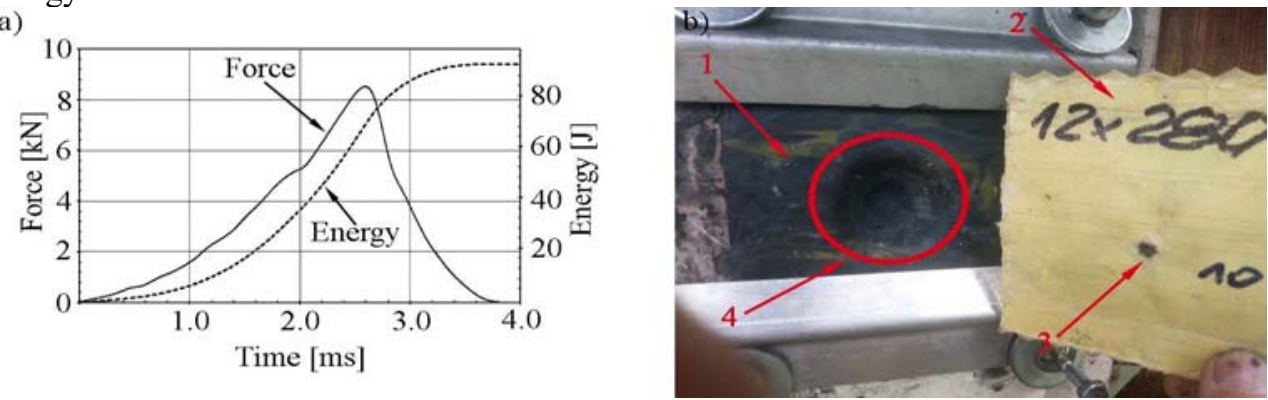

Fig. 2. Selected recorded results: a) after piercing on the drop test, b) after shooting into the laminate: 1 - clamping and the support base for the sample, 2 - shot sample, 3 - penetration point of the projectile in the laminate, 4 - bending region in the plasticine base.

In the drop test, the average energy absorbed by the laminate settles at $92.9 \mathrm{~J}$ with an average impact speed of the impactor at $8.8 \mathrm{~m} / \mathrm{s}$, the force which acted on a sample was $8.5 \mathrm{kN}$. Registered laminate deformation is $21.95 \mathrm{~mm}$. During the ballistic test, samples absorbed the total kinetic energy (488.9 J), which was distributed on the deformation of the projectile and the deformation of the laminate. Dynamic deflection of $28 \mathrm{~mm}$ of the laminate and the local influence area of approx. $36 \mathrm{~cm}^{2}$ were estimated based on the stamped in the plasticine cavity.

\subsection{The SEM analyses of the composites}

By using the Scanning Electron Microscope (SEM), an in-depth analysis of the matrix and the strengthening of the material as a result of the impact were carried out. Based on the SEM images it is shown that the laminate is properly saturated with the resin, as the resin is present between individual strands of fiber. As show in Figure 3, in the contact section between the impactor and the laminate, the reinforcing fibers in the composite are sheared and the damage of the matrix is related with compression and shearing of the fibers, which is observed as delamination.
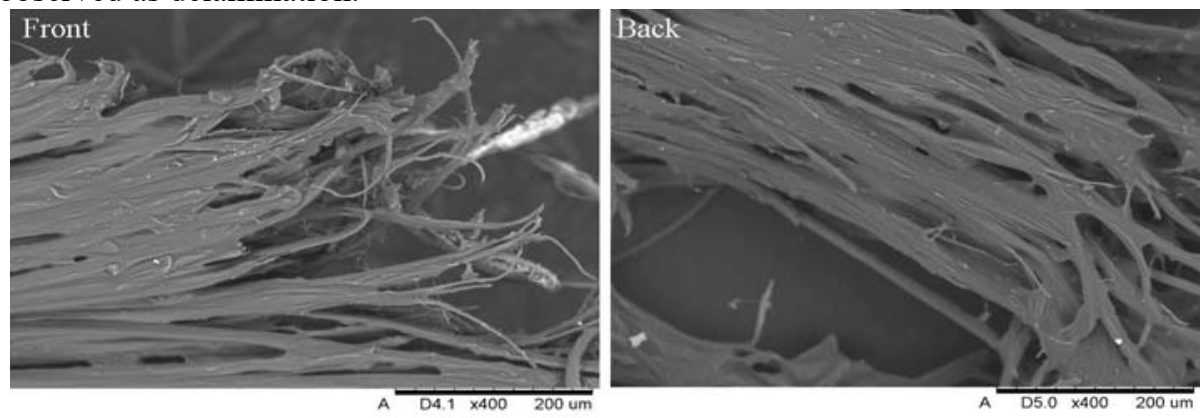

Fig. 3. SEM image of the damage from the drop test. 
At the rear part of the laminate fibers are stretched by the impactor and their shearing occurs to a lesser degree. Visible damage to the matrix is a result of fiber delamination.

Damage to the reinforcement layer and the matrix from firing a $9 \mathrm{~mm}$ Parabellum bullet is show in Figure 4.
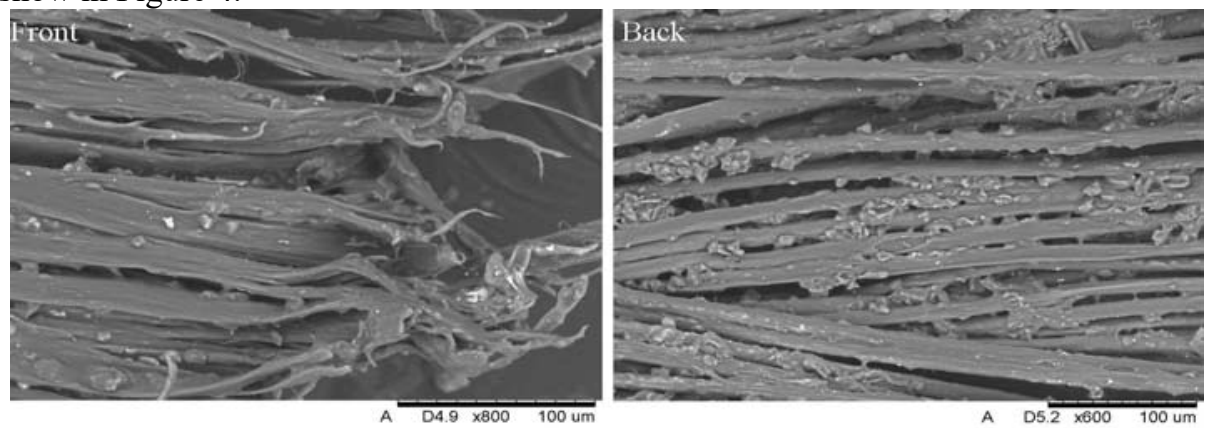

Fig. 4. SEM image of the damage in a sample after the ballistic test.

At the start, the difference in the damage of the reinforcement is visible. This difference is due to the fact that, for the ballistic testing, there is a deformation of the projectile, where the frontal surface is increased, and thus to a large extent the matrix takes an important function. It can be concluded that the matrix significantly affects the dissipation of the energy absorbed by the shot sample.

\subsection{Energy absorption in simulation by FEM}

Conducting an analysis while using the Finite Element Method (FEM), a model which enhances the dissipation of the impact energy was developed. As shown in Figure 5a, the dissipation of kinetic energy and the extent of deformation (Figure 5b) were correctly interpreted.

a)

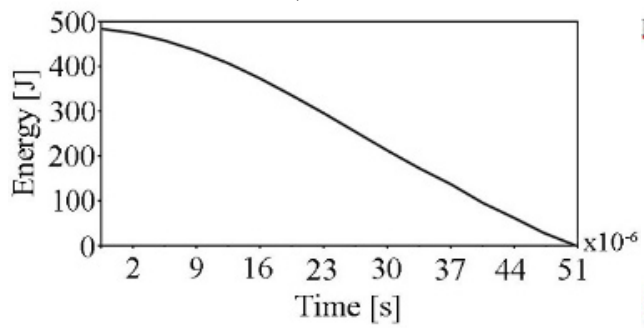

b)

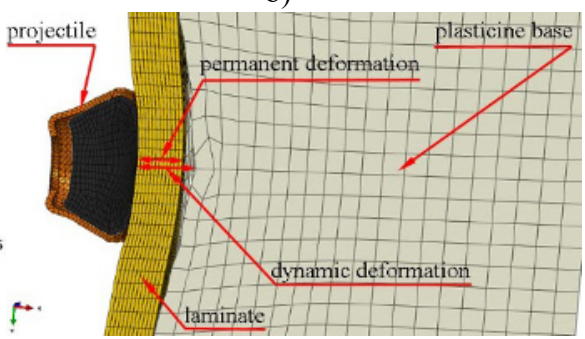

Fig. 5. Results of the numerical analysis: a) graph of the impact kinetic energy, b) deformation of the laminate.

\section{Conclusions}

This work is considered as an initial research of testing laminates composed of aramid fabric with DCPD resin matrix. Samples were subjected to tests, performed on a droptower and ballistic tests. Energy dissipation was compared at low (drop test) and high (ballistic test) load speeds. It was observed that there was a higher efficiency of the matrix at high loads. As a result of microscopic examination, correct saturation of the reinforcement in the matrix was concluded. Used DCPD resin satisfies the requirements in terms of energy absorption. 
As observed in the SEM images, the resin saturates the reinforcement to such a degree that it does not cause the embrittlement of the fiber, which can be observed in the case of epoxy resins and glass fiber. In the following research, work of the authors will focus on various climatic conditions, taking into consideration the aging process, mainly the aging of the matrix.

Calculations have been carried out in Wroclaw Centre for Networking and Supercomputing (http://www.wcss.pl), grant No. 74

\section{References}

1. A. Abe, H-H, Hans-Henning Kausch, M. Möller, H. Pasch, Polymer Composites Polyolefin Fractionation - Polymeric Peptidomimetics - Collagens (Springer-Verlag, Berlin Heidelberg, 2013)

2. R. F. Gibson, Principles of composite material mechanics (Third edition, Boca Raton, CRC Press: Taylor \& Francis Group, 2012)

3. W. Barnat, P. Dziewulski, T. Niezgoda, R. Panowicz, Application of composites to impact energy absorption, Computational Materials Science 50, 4, 1233-1237 (2011)

4. A. K. Bandaru Chavan, S. Ahmad, R. Alagirusamy, N. Bhatnagar, Ballistic impact response of Kevlar ${ }^{\circledR}$ reinforced thermoplastic composite armors, Int. J. Impact Eng. 89, 1-13 (2016)

5. J. G. Carrillo, R. A. Gamboa, E. A. Flores-Johnson, P. I. Gonzalez-Chi, Ballistic performance of thermoplastic composite laminates made from aramid woven fabric and polypropylene matrix, Polymer Testing 31, 512-519 (2012)

6. M. Bocian, K. Jamroziak, M. Kosobudzki, The analysis of energy consumption of a ballistic shields in simulation of mobile cellular automata, Advanced Materials Research 1036, 680-685 (2014)

7. L. Iannucci, R. Dechaene, M. Willows, J. Degrieck, A failure model for the analysis of thin woven glass composite structures under impact loadings, Computers and Structures 79, 8, 785-799 (2001)

8. R. H. Zee, C. Y. Hsieh, Energy loss partitioning during ballistic impact of polymer composites, Polymer Composites 14, 3, 265-271( 1993)

9. S. A. Salpekar, Analysis of delamination in cross-ply laminates initiating from impact induced matrix cracking, Journal of Composites Technology and Research 15, 2, 88-94 (1993)

10. T. J. Kang, C. Kim, Impact energy absorption mechanism of largely deformable composites with different reinforcing structures, Fibers and Polymers 1, 1, 45-54 (2000)

11. P. J. Hogg, Composites for ballistic applications, Journal of Composites Processing (CPA, Bromsgrove U K, March, 2003)

12. J. Pach, D. Pyka, K. Jamroziak, P. Mayer, The experimental and numerical analysis of the ballistic resistance of polymer composites, Composites Part B: Engineering 113, 24-30 (2017)

13. A. Fürstner, L. Ackermann, B. Gabor, R. Goddard, C. W. Lehmann, R. Mynott, F. Stelzer, O. R. Thiel, Comparative Investigation of Ruthenium-Based Metathesis Catalysts Bearing N-Heterocyclic Carbene (NHC) Ligands, Chem. Eur. J. 7, 15, 32363253 (2001)

14. M. Bocian, K. Jamroziak, M. Kosobudzki, Analysis of material punching including a rotational speed of the projectile, Solid State Phenomena 220-221, 571-576 (2015) 